\title{
Image-guided Stereotactic Body Radiotherapy in Metastatic Prostate Cancer
}

\author{
FRANCESCO PASQUALETTI $^{1}$, MARCO PANICHI ${ }^{1}$, ALDO SAINATO $^{1}$, DAVIDE BALDACCINI $^{1}$, \\ PAOLA COCUZZA ${ }^{1}$, ALESSANDRA GONNELLI $^{1}$, SABRINA MONTRONE ${ }^{1}$, \\ ALESSANDRO MOLINARI ${ }^{1}$, SARA BARBIERO ${ }^{2}$, ANDREA BRUSCHI ${ }^{2}$, ELISA NOTINI ${ }^{1}$, \\ STEFANO URSINO ${ }^{1}$, VALENTINA MAZZOTTI ${ }^{3}$, RICCARDO MORGANTI ${ }^{3}$, \\ GABRIELE CORAGGIO $^{4}$, MARTINA CANTARELLA ${ }^{2}$, PAOLA ANNA ERBA ${ }^{5}$ and FABIOLA PAIAR ${ }^{1}$ \\ ${ }^{1}$ Radiation Oncology, Pisa University Hospital, Pisa, Italy; \\ ${ }^{2}$ Radiation Oncology, Casa di Cura SanRossore, Pisa, Italy; \\ ${ }^{3}$ Statistical Analysis Unit, Pisa University Hospital, Pisa, Italy; \\ ${ }^{4}$ Radiation Oncology, Hopitaux Universitaires Henri Mondor APHP, Créteil, France; \\ ${ }^{5}$ Nuclear Medicine, Pisa University Hospital, Pisa, Italy
}

\begin{abstract}
Background/Aim: In the last years, the use of Image Guided Stereotactic Radiotherapy (IG-SBRT) in patients with metastatic prostate cancer has increased. In this study, we aimed to assess the role of IG-SBRT in terms of local control and safety in patients with metastatic prostate cancer. Materials and Methods: Primary and secondary endpoints of this prospective observational study were local control and safety related to IG-SBRT. All lesions were treated with 24 Gy as a single fraction or 27 Gy in 3 fractions. After SBRT, Systemic therapies were administered only after the occurrence of more than three synchronous active lesions in oligometastatic patients (patients with less than 4 active synchronous lesions) or new lesions occurrence in patients with more than 3 synchronous lesions. Results: From April 2011 to June 2017, 78 metastatic lesions (32 bone and 46 node) from 51 patients with prostate cancer were treated. After a median follow-up of 18.5 months (range=3-103 months), only 2 lesions (4\%) relapsed inside the radiation field. All local recurrences were located on the bone. Estimated 12 and 24 months local control ratios were 98.7 and 97.4\%, respectively. Except for one case, toxicity greater than $G 2$ was not recorded. Conclusion: IG-SBRT is safe and can be considered as a valid therapy in patients with metastatic prostate cancer requiring a long-lasting metastases control.
\end{abstract}

Correspondence to: Francesco Pasqualetti, MD, Ph.D., Radiation Oncology, Pisa University Hospital, Via Roma 67, 56123, Pisa, Italy. Tel: +39 3479356905, Fax: +39 050993456, e-mail: francep24@hotmail.com,f.pasqualetti@ao-pisa.toscana.it

Key Words: Metastatic prostate cancer, image guided radiotherapy, stereotactic body radiotherapy, oligometastatic patients.
In the past 10 years, advances obtained in radiotherapy delivering and treatment planning have allowed radiation oncologists to reconsider the approach for metastatic lesions, not only with a palliative/symptomatic intent, but also as an ablative local treatment. In the last few years, after the development of new drugs and the consequent improvement in life expectancy, radiotherapists are often asked to deliver high dose of ionizing radiations to achieve control of metastatic lesions and the related symptoms, whenever present, for a longer period than in the past (1-3). As a consequence, in patients with metastatic prostate cancer, the use of stereotactic body radiotherapy (SBRT), the most appropriate technique to deliver high dose radiotherapy to a target lesion, has been increased $(4,5)$. Recently, the advent of image-guided radiotherapy (IGRT) has made possible to obtain both tumor control and adequate safe profile (6-8).

However, despite the extensive research, the role of Image Guided Stereotactic Body Radiotherapy (IG-SBRT) in patients with metastatic prostate cancer has not been fully addressed yet. The administration of systemic therapy, either hormonal therapy or chemotherapy, makes it difficult to evaluate the effect of radiotherapy on local control (9). In this prospective observational monocentric study, avoiding any influence of systemic therapy, we assessed the role of IG-SBRT in terms of local control and safety in patients with metastatic prostate cancer.

\section{Materials and Methods}

Patients. Findings reported in the present study have been collected prospectively after local IRB gave its approval. Data analysis was performed in September 2017. Every patient had to meet the following inclusion criteria in order to be included in the present study: age greater than 18 years, histological diagnosis of prostate 
cancer, metastatic lesions detected and assessed using choline $\mathrm{PET} / \mathrm{CT}$, not requiring systemic therapy (either hormonal therapy or chemotherapy) after IG-SBRT, detectable PSA value.

Six weeks after SBRT, and then every three months, patients were assessed by measuring total PSA value. In order to identify relapse of treated lesions or lesions outside the irradiated field, a new Choline PET/CT was performed after PSA failure. After SBRT, systemic therapies (hormonal therapy or chemotherapy) were administered only after the occurrence of more than three synchronous active lesions in oligometastatic patients (patients with less than 4 active synchronous lesions) or new lesions occurrence in patients with more than 3 synchronous lesions.

All procedures performed in studies involving human participants were in accordance with the ethical standards of the institutional and national research committee and with the 1964 Helsinki declaration and its later amendments or comparable ethical standards. This article does not contain any studies with animals performed by any of the authors. Considering the study design (data were collected prospectively without any interference with clinical decision making) formal consent was not required.

Treatment procedure. IG-SBRT treatments were performed using Varian True Beam ${ }^{\circledR}$ platform and 6-MV photons with flattening filter-free beams. RapidArc ${ }^{\circledR}$ system was used for treatment planning. Axial Computer Tomography (CT) images were obtained using a Light Speed RT 16-slice simulator (GE HealthCare, Chalfont St Giles, UK). The CT image slice was $1.25-\mathrm{mm}$. Target lesions (Gross Tumor Volume (GTV) were identified using choline $\mathrm{PET} / \mathrm{CT}$ images. Planning target volume consisted of an isotropic 3 mm expansion of the Clinical Target Volume (CTV). Metastatic lesions were treated with $24 \mathrm{~Gy}$ as a single fraction or using a hypofractionated schedule, $27 \mathrm{~Gy}$ in three fractions ( 2 or 3 fractions a week). The choice of dose and fractionation depended on tumor volume and location (proximity to critical structures such as bowel or great vessels). Delivered dose was prescribed to the periphery of the target. Before each fraction, a cone-beam CT was performed for patient's set-up. Task group 101 of the American Association of Physicists in Medicine constraints were used to avoid toxicity of the organs at risk (10). Toxicity was recorded using the Common Terminology Criteria for Adverse Events (CTCAE), version 4.0.

Statistical analyses. Primary endpoint of this study was concerned with the time to progression of treated lesions. Secondary endpoint was the safety related to SBRT. Local failure was assessed using choline PET/CT imaging. All intervals were measured from SBRT to event occurrence (local failure). To avoid interference related to systemic therapy on local control patient, follow-up was censored at the last follow-up or at the time of systemic therapy administration. Kaplan-Meier method and Cox proportional hazard models were used to analyse time-to-event variables and factors associated with primary and secondary objectives, respectively. Gleason Score, Radiotherapy dose, metastasis site (bone or lymph node), conformity index and clinical target volume were chosen to be considered in the univariate analysis.

\section{Results}

From April 2011 to June 2017, 78 metastatic lesions (32 bone and 46 node) from 51 patients with prostate cancer were treated with IG-SBRT at the Radiation Oncology Unit of the University Hospital of Pisa. Baseline clinical characteristics and radiation related parameters are reported in Table I. Overall, 28 patients were treated with 24 Gy as a single fraction whereas 50 with 27 Gy in 3 fractions.

After a median follow-up of 18.5 months (range=3-103 months), only 2 lesions $(2.56 \%$ ) relapsed inside the radiation field. All the local recurrences were located on the bone. Estimated 12 and 24 months local control ratios were 98.7 and $97.4 \%$, respectively. Considering the small number of events, the planned univariate and multivariate analyses were not performed; however, follow-up is still ongoing. Local control time is reported in Figure 1.

With the exception of one vertebral fracture (G3 toxicity) related to stereotactic body radiotherapy, toxicity greater than G2 was not recorded.

\section{Discussion}

In this prospective monocentric observational study, we reported the experience of the University Hospital of Pisa in treating patients with metastatic prostate cancer with IG-SBRT. In order to avoid any interference of oncology agents with ionizing radiations we decided to censor patients at the time of death or starting systemic therapy after SBRT. Despite the research on the role of IGRT on the management of patients with metastatic cancer, many studies did not contemplate to stop systemic therapy at the time of SBRT, thus, their design makes difficult to assess the role of ionizing radiations on metastases control and, therefore, on symptoms control $(9,11)$.

After a median follow-up of 18.5 months, only 2 recurrences inside the treatment field were observed and 12 and 24-month control ratios were 98.7 and $97.4 \%$, respectively. Since 2013, several studies aimed to assess the role of stereotactic radiotherapy in patients with oligometastatic cancer, reporting encouraging results $(4,7$, 12-15). However, literature includes studies with a large variability in dose and radiotherapy techniques, and the main endpoint was set on the systemic impact of SBRT instead of metastases control. Authors reported outcome on local control in more than $90 \%$ of prostate cancer treated lesions. In 2013, Berkovic et al. first reported results obtained in a series of patients treated with SBRT (50 Gy in 10 fractions) to postpone the beginning of hormonal therapy (4). After a median follow-up of 24 months, the author reported a 2-year local control of $100 \%$. Even Decaesteker and Triggiani, reported similar results in terms of local control in their series not conditioned by systemic therapy $(13,16)$. It is important to note that the findings reported in the present study are also consistent with results from our institution published in 2016 in a prospective study on oligometastatic prostate cancer; after having treated 29 patients with IGSBRT, with a median follow-up of 11.5 months, where local failure was not observed at all (7). 
Table I. Basal clinical characteristics of patients and dosimetric parameters.

\begin{tabular}{lr}
\hline Number of patients & 51 \\
High Risk & 18 \\
Intermediate Risk & 27 \\
Low Risk & 6 \\
Metastatic state (at last treatment) & 34 \\
Oligo Mts & 17 \\
Multi Mts & 78 \\
Number of treatments & 32 \\
Bones & 46 \\
Nodes & 2 \\
Patients treated with 5 SBRT & 2 \\
Patients treated with 4 SBRT & 3 \\
Patients treated with 3 SBRT & 5 \\
Patients treated with 2 SBRT & 39 \\
Patients treated with 1 SBRT & \\
Medium volume & (range=0.3-49.5) \\
5,185 cc & \\
Sistemic control & \\
Yes 31 & \\
No 47 & \\
Local control & \\
Yes 76 & \\
No 2 & \\
DOSE & \\
24 Gy & \\
900 Gy *3 & \\
\hline
\end{tabular}

Radiobiological fundamentals suggest that tumor control after conventional multi-fractionated radiotherapy is mostly achieved through DNA damage due to direct effect of ionizing radiations (17). Nevertheless, in patients with metastatic prostate cancer, classical doses and fractionations allow local control after radiotherapy for a few months only (18). After that length, symptoms related to metastatic lesions appear. Although little is known on the effect of high dose irradiation on metastatic prostate cancer, preclinical studies have addressed this topic (19-22). Unlike conventional radiotherapy high dose radiotherapy, in addition to causing DNA damage and cell death, results in endothelial damage, vascular occlusion and tumor cell death $(19,21,23)$. Thus, the efficacy of metastasis control through IGRT seems to be durable, suggesting that patients with a good prognosis that need to control symptoms, due to metastatic lesions, for several years can be considered for this local treatment. The clinical beneficial impact of achieving local control in patients with metastatic prostate cancer includes an improved quality of life free of pain and side effects of antalgic drugs (24).

In our series, we recorded only a G3 toxicity (vertebral fracture). These results confirm what is already reported by previous studies about the safety of IGRT and the optimal therapeutic ratio $(4,5)$.

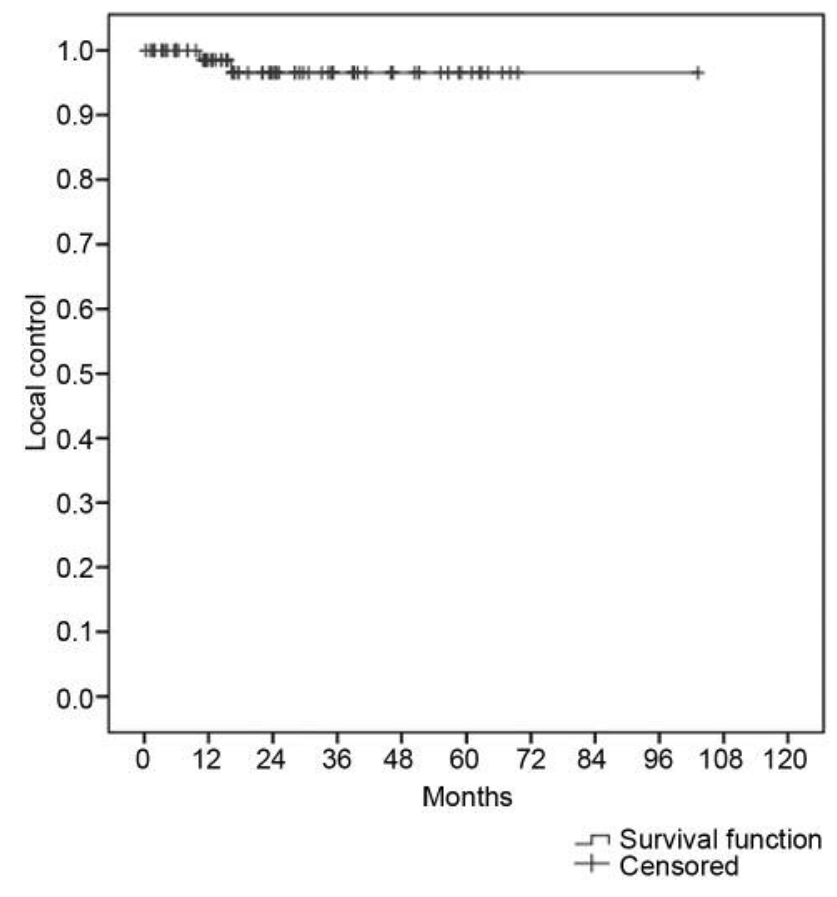

Figure 1. Local control after stereotactic body radiotherapy.

\section{Conclusion}

Considering the long-lasting metastasis control and safety, IGRT can be considered in patients with metastatic prostate cancer as an ablative local treatment.

\section{Conflicts of Interest}

The Authors declare that they have no conflicts of interest.

\section{Acknowledgements}

The Authors thank Duccio Volterrani, Andrea Madonna and Francesco Cartei for their collaboration in the present study.

\section{References}

1 Danila DC, Morris MJ, de Bono JS, Ryan CJ, Denmeade SR, Smith MR, Taplin ME, Bubley GJ, Kheoh T, Haqq C, Molina A, Anand A, Koscuiszka M, Larson SM, Schwartz LH, Fleisher M and Scher HI: Phase II multicenter study of abiraterone acetate plus prednisone therapy in patients with docetaxel-treated castrationresistant prostate cancer. J Clin Oncol 28: 1496-1501, 2010.

2 Taneja SS: Re: Increased survival with enzalutamide in prostate cancer after chemotherapy. J Urol 189: 123-124, 2013. 
3 Siegel RL, Miller KD, and Jemal A: Cancer statistics, 2018. CA Cancer J Clin 68: 7-30, 2018.

4 Berkovic P, De Meerleer G, Delrue L, Lambert B, Fonteyne V, Lumen N, Decaestecker K, Villeirs G, Vuye P and Ost P: Salvage stereotactic body radiotherapy for patients with limited prostate cancer metastases: deferring androgen deprivation therapy. Clin Genitourin Cancer 11: 27-32, 2013.

5 Ost P, Jereczek-Fossa BA, As NV, Zilli T, Muacevic A, Olivier K, Henderson D, Casamassima F, Orecchia R, Surgo A, Brown L, Tree A, Miralbell R and De Meerleer G: Progression-free survival following stereotactic body radiotherapy for oligometastatic prostate cancer treatment-naive recurrence: A multi-institutional analysis. Eur Urol 69: 9-12, 2016.

6 Tree AC, Khoo VS, Eeles RA, Ahmed M, Dearnaley DP, Hawkins MA, Huddart RA, Nutting CM, Ostler PJ and van As NJ: Stereotactic body radiotherapy for oligometastases. Lancet Oncol 14: e28-37, 2013.

7 Pasqualetti F, Panichi M, Sainato A, Matteucci F, Galli L, Cocuzza P, Ferrazza P, Coraggio G, Pasqualetti G, Derosa L, Sollini M, Mannelli L, Ortori S, Monzani F, Ricci S, Greco C, Fabrini MG and Erba PA: [(18)F]Choline PET/CT and stereotactic body radiotherapy on treatment decision making of oligometastatic prostate cancer patients: preliminary results. Radiat Oncol 11: 9, 2016.

8 Pasqualetti F, Montrone S, Vivaldi C, Zani M, Fedele D, Fornaro L, Pasqualetti G, Salvatore L, Manfredi B, Laliscia C, Coraggio G, Gonnelli A, Loupakis F, Masi G, Sainato A, Monzani F, Falcone A and Paiar F: Stereotactic body radiotherapy in patients with lung oligometastases from colorectal cancer. Anticancer Res 37: 315-319, 2017.

9 Greco C, Zelefsky MJ, Lovelock M, Fuks Z, Hunt M, Rosenzweig K, Zatcky J, Kim B and Yamada Y: Predictors of local control after single-dose stereotactic image-guided intensity-modulated radiotherapy for extracranial metastases. Int J Radiat Oncol Biol Phys 79: 1151-1157, 2011.

10 Benedict SH, Yenice KM, Followill D, Galvin JM, Hinson W, Kavanagh B, Keall P, Lovelock M, Meeks S, Papiez L, Purdie T, Sadagopan R, Schell MC, Salter B, Schlesinger DJ, Shiu AS, Solberg T, Song DY, Stieber V, Timmerman R, Tome WA, Verellen D, Wang L and Yin FF: Stereotactic body radiation therapy: the report of AAPM Task Group 101. Med Phys 37: 4078-4101, 2010.

11 Filippi AR, Badellino S, Ceccarelli M, Guarneri A, Franco P, Monagheddu C, Spadi R, Ragona R, Racca P and Ricardi U: Stereotactic ablative radiation therapy as first local therapy for lung oligometastases from colorectal cancer: a single-institution cohort study. Int J Radiat Oncol Biol Phys 91: 524-529, 2015.

12 Pasqualetti F, Cocuzza P, Coraggio G, Ferrazza P, Derosa L, Galli L, Pasqualetti G, Locantore L, Boni R, Fabrini MG and Erba PA: Long-Term PSA control with repeated stereotactic body radiotherapy in a patient with oligometastatic castrationresistant prostate cancer. Oncol Res Treat 39: 217-220, 2016.
13 Decaestecker K, De Meerleer G, Lambert B, Delrue L, Fonteyne V, Claeys T, De Vos F, Huysse W, Hautekiet A, Maes G and Ost P: Repeated stereotactic body radiotherapy for oligometastatic prostate cancer recurrence. Radiat Oncol 9: 135, 2014.

14 Rades D, Blanck O, Khoa MT, P VANT, Hung NQ, Dziggel L and Schild SE: Validation of a survival score for patients receiving radiosurgery or fractionated stereotactic radiotherapy for 1 to 3 brain metastases. In Vivo 32: 381-384, 2018.

15 Tyran M, Charrier N, Darreon J, Madroszyk A, Tallet A and Salem N: Early PET-CT after stereotactic radiotherapy for stage 1 non-small cell lung carcinoma is predictive of local control. In Vivo 32: 121-124, 2018.

16 Triggiani L, Alongi F, Buglione M, Detti B, Santoni R, Bruni A, Maranzano E, Lohr F, D'Angelillo R, Magli A, Bonetta A, Mazzola R, Pasinetti N, Francolini G, Ingrosso G, Trippa F, Fersino S, Borghetti P, Ghirardelli P and Magrini SM: Efficacy of stereotactic body radiotherapy in oligorecurrent and in oligoprogressive prostate cancer: new evidence from a multicentric study. Br J Cancer 116: 1520-1525, 2017.

17 Pajonk F, Vlashi E and McBride WH: Radiation resistance of cancer stem cells: the 4 R's of radiobiology revisited. Stem Cells 28: 639-648, 2010.

18 Meeuse JJ, van der Linden YM, van Tienhoven G, Gans RO, Leer JW, Reyners AK and Dutch Bone Metastasis Study G: Efficacy of radiotherapy for painful bone metastases during the last 12 weeks of life: results from the Dutch Bone Metastasis Study. Cancer 116: 2716-2725, 2010.

19 Brown JM, Carlson DJ and Brenner DJ: The tumor radiobiology of SRS and SBRT: are more than the 5 Rs involved? Int J Radiat Oncol Biol Phys 88: 254-262, 2014.

20 Brown JM, Diehn M and Loo BW Jr.: Stereotactic ablative radiotherapy should be combined with a hypoxic cell radiosensitizer. Int J Radiat Oncol Biol Phys 78: 323-327, 2010.

21 Song CW, Kim MS, Cho LC, Dusenbery K and Sperduto PW: Radiobiological basis of SBRT and SRS. Int J Clin Oncol 19: 570-578, 2014.

22 Clement JJ, Tanaka N and Song CW: Tumor reoxygenation and postirradiation vascular changes. Radiology 127: 799-803, 1978.

23 Song CW, Park I, Cho LC, Yuan J, Dusenbery KE, Griffin RJ and Levitt SH: Is indirect cell death involved in response of tumors to stereotactic radiosurgery and stereotactic body radiation therapy? Int J Radiat Oncol Biol Phys 89: 924-925, 2014.

24 Reale C, Turkiewicz AM and Reale CA: Antalgic treatment of pain associated with bone metastases. Crit Rev Oncol Hematol 37: 1-11, 2001 